\title{
Pathways of Business Talents' Cultivation: A Case Study
}

\author{
Baoqing Cheng ${ }^{1, a, *}$, Caifu Ye $\mathrm{e}^{1, \mathrm{~b}}$ \\ ${ }^{1}$ School of Management, Shanghai Normal University Tianhua College, 1661 North Shengxin Road, Jiading \\ District, Shanghai, China \\ ${ }^{2}$ Shanghai Normal University Tianhua College, 1661 North Shengxin Road, Jiading District, Shanghai, \\ China \\ a baoqingch@126.com, b cfye@163.com \\ *corresponding author
}

Keywords: Business talents’ cultivation, business school, higher education.

\begin{abstract}
To provoke discussion amongst colleagues in the field of higher business education around the world, the paper provides a case study of the business school education of a private university in Shanghai, China. Through over 12 years' effort, distinctive educational characteristics have come into being. In summary, the business school have adopted four main pathways in cultivating its students into business talents, namely (1) constantly optimizing programs along with local economy and society development; (2) constantly improving curriculum in accordance with industry and job requirements; (3) promoting students' expertise and critical thinking through dynamic classroom; and (4) improving students' comprehensive quality and ability through "Three Focusing and Three Persistence”.
\end{abstract}

\section{Introduction}

To provoke discussion amongst colleagues in the field of higher business education around the world, the paper provides a case study of the business school education of a private university in Shanghai, China---Shanghai Normal University Tianhua College. Approved by the national Ministry of Education and established in 2005, this university is among the first non-profit applied technical multi-disciplinary private institutions in Shanghai. Recruiting students from 27 provinces and cities nationwide (except Beijing and Tianjin), there are over 9200 full-time undergraduate students on campus in 2018. The School of Management of the university has six business-related programs including Financial Management, International Business, Logistics Management, Tourism Management, Financial Mathematics, and Financial Management (CFA, Chartered Financial Analyst-oriented).

\section{Pathways of Business Talents' Cultivation}

To cultivate its students into qualified business talents, the School of Management of the university have abided by following pathways.

\subsection{Constantly Optimizing Programs along with Local Economy and Society Development}

The School of Management constantly optimizes programs according to the characteristics and trends of the mobile internet era as well as the development of Yangtze River Delta region, especially of Shanghai local economy.

In recent years, "International Enterprise Management" Orientation has been added to the International Business Program on basis of the original "International Trade Affairs" Orientation. Besides, the Tourism Management program has gradually set up three orientations including Theme Park Operation, Outbound Tourism Leader and Tourism E-commerce.

In 2017, the School of Management set up two new programs: Financial Mathematics and Financial Management (CFA-oriented). Cooperating with West Virginia University, the latter 
program adopts a “ $3+1+2$ ” model (i.e., 3 years' undergraduate study in Tianhua College, one year undergraduate study in West Virginia University, plus an optional two years' master study in West Virginia University). The program adheres to the principle of "joint cultivating, faculty exchange, curriculum integration, credit recognition, and master pathway" in conducting cooperation and implantation of the international curriculum.

In 2017, the School of Management also applied for the establishment of a new program named Internet Finance which is under municipal Education Commission's approving now.

The setup of new programs and new orientations is based on extensive research and surveys. Take the Tourism E-commerce Orientation as an example, which was added to the tourism management program in 2016. The faculty of Tourism Management program visited more than 20 typical enterprises during 2014-2015 to carry out studies on human resources developing trends in tourism industry. The enterprises they visited include traditional tourism companies and new types of tourism companies such as OTA, B2B tourism platform enterprises, UGC tourism companies, and so on. On the basis of comprehensive and deep investigation and study, the Tourism Ecommerce orientation has been set up with a clear cultivation goal and a deep understanding of the requirements for related job positions in the tourism e-business field.

\subsection{Constantly Improving Curriculum in accordance with Industry and Job Requirements}

Under the organization of Academic Affairs Office, every program revises curriculum annually. On the premise of maintaining stability as well as wholeness of the curriculum system, some courses may be added or cancelled according to the overall changes in the industry. For example, in 2014, the Logistics Management program added three optional courses including automotive logistics, e-commerce logistics and cold chain logistics; in 2015, Financial Management program added several optional courses on internet finance in the model of series of lectures by industry experts. In accordance with the job requirements for knowledge, ability as well as quality in the field of tourism e-commerce, seven new courses were designed for Tourism E-commerce orientation including "tourism e-commerce foundation", "tourism e-commerce operation", "tourism website design", "tourism e-commerce customer service", "tourism products” ,"tourism network marketing” and "tourism big data analysis". It is an innovation on program and curriculum.

\subsection{Promoting Students' Expertise and Critical Thinking through Dynamic Classroom}

In 2013, the School of Management carried out an overall teaching reform, requiring all faculty members to redesign and implement an optimized syllabus with the emphasis on promoting students' participation as well as learning outcomes. Different from most former syllabi, new syllabi have more contents. They include not only course introduction, learning objectives, assessment composition, teaching themes and content of each class, but also detailed preview requirements for each class and after-class individual and group work requirements. In addition, assessment of students' performance is no longer composed of several simple parts, but includes classroom performance, tests, after-class individual and group work performance, theses, final exams, and so on. The proportion of each part varies depending on the nature and content of the course and the design of the instructor.

Since 2016, Shanghai Normal University Tianhua College has vigorously promoted the "Dynamic Classroom Teaching Reform" in order to further improve teaching quality and effectiveness and make the classroom "dynamic". The reform advocates that teachers should focus on students' growth, elaborately implement syllabus optimization, organize dynamic classroom teaching and establish rich course resources after conducting deep study of classroom, teaching methods as well as individual development of each student. All faculty of the School of Management have participated in the reform. Through the reform and series of investigation and discussion, the whole university has developed a teaching model which links up pre-class selfstudying, mid-class collaboration and post-class exploration. The university has also designed a new evaluation system after carrying out hundreds of classroom observing, experts' evaluation and nearly one thousand students' questionnaire investigation. 


\section{Improving Students' Comprehensive Quality and Ability through "Three Focusing and Three Persistence”}

Cultivation of students not only happens in classroom learning, but also outside of classroom. In terms of cultivating students, especially in turning every student into a whole citizen, the university, with its "learning for behaving" motto, has a complete set of unique practices which can be summed up as "Three Focusing and Three Persistence”.

\section{1 "Three Focusing"}

The first focusing is to focus on morning and evening English study. Shanghai Normal University Tianhua College has strict morning and evening study requirements for freshmen and sophomores. The university spent six million RMB to shoot a total of more than 900 episodes of teaching video named "Tianhua grows with you" which is divided into 5 series and maintains a very high level in contents and quality. The English series can help students strengthen their English learning foundation and more easily pass CET-4 and CET-6 examinations. They contain training from vocabulary to grammar, from spoken English to classic speeches. Through two years' morning and evening English study, students can have more solid language foundation for conducting latter internationalized study. In addition to English series, the other four series have also been gradually used in compulsory or elective general-education courses. The Sinology series interpret more than ten Chinese classics; the series of "Tianhua Teaches You How to Think" explain the concept and steps of design thinking; the series of "How to Be a Whole Citizen" educate students to be good citizens with high sense of social responsibility; the series of "Look at the World" teach students to correctly understand the world and form their own social values. The atmosphere of "learning hard and striving to make progress" has been improved since the introduction of video series. Most of all, this measure eliminates the wrong tendency commonly existed in college freshmen, namely "I can relax at university and no long need self-management". It also helps them develop the concept of cherishing time.

The second focusing is to focus on the reading of thirty classics. As early as 6 years ago, the university launched the "classic reading project", which designated 30 classic books that must be read during students' four years of university study. To ensure this project being carried out well, the university organizes various guide-reading lectures, discussion seminars and exhibitions in every semester to help students read and understand classics. As the saying goes, "knowledge makes a gentleman”. The university hopes to cultivate more civilized and refined young people by creating a strong and sophisticated reading atmosphere.

The third focusing is to focus on the bilingual debate training in which all students involved. Whether the promotion of dynamic classroom or the severe tests from the workplace and career development faced by students in the future, it is of vital importance for students to have a good eloquence and ability to find sufficient arguments to criticize and query. To change Chinese students from quiet and passive learners into more active learner who are willing and able to express their own views, the university has proposed and carried out bilingual debate training for all students which requires every student to express his own views and seek arguments with partners on social hot issues as well as key issues in students' growing-up, not only in mother tongue, but also in English.

Advocating students to study English in the morning and evening is to boost good learning atmosphere. Advocating students to read 30 classic books is to cultivate their inner cultural accomplishment. Advocating students to debate bilingually is to improve students' creative thinking ability and eloquence.

\section{2 “Three Persistence”}

The first persistence is to persist in the collaborative management of dual counsellor team. The university has two counsellor teams: while members of both teams have upright qualities, one team is the chief counsellor team, the members of which have Master's degrees and are responsible for students' moral education, guidance of learning and career development, the other is vice counsellor 
team composed of veterans who have rich management experiences and are mainly responsible for the regular physical training of students, discipline development as well as campus security. Two teams conduct a full-time and all-round management on students by linking up with each other on time and cooperating with each other at work.

The second persistence is to persist in the moral credit system which has been implemented for more than 6 years. The system incorporates the cultivation of students' morality, behaviour norms, quality development and civic spirit into a unified evaluation.

The third persistence is to persist in students' self-management, which is mainly achieved through various assistant systems. For example, through the class assistant system, outstanding sophomores and juniors assist freshmen quickly adapt to new learning and living environment. They also set good models for freshmen. The management of moral credit system mentioned the second persistence is also implemented and supervised by students.

The university persists in dual counsellor teams to emphasize on discipline. The university persists in moral credit system to emphasize self-discipline. And the university persists in student self-management to emphasize demonstration or setting models.

\section{Conclusion}

This paper presents the major pathways taken by the School of Management of a private university in Shanghai to cultivate its students into qualified business talents. The pathways are: (1) constantly optimizing programs along with local economy and society development; (2) constantly improving curriculum in accordance with industry and job requirements; (3) promoting students' expertise and critical thinking through dynamic classroom; and (4) improving students' comprehensive quality and ability through "Three Focusing and Three Persistence”. Although each university has its own way in talent-cultivation and there are hot debates on how to promote business education ${ }^{[1]-[5]}$, the authors of the paper hopes their practices could be of some reference value to some universities.

\section{References}

[1] Pincus, K.V., Stout, D.E., Sorensen, J.E., Stocks, K.D., and Lawson, R.A. (2017) Forces for Change in Higher Education and Implications for the Accounting Academy. Journal of Accounting Education, 40, 1-18.

[2] Xia, X. (2012) Study on the Undergraduate Cultivation Mode in Ivey Business School and the Enlightenment. Future and Development, 5, 86-90.

[3] Minocha, S., Reynolds, M., and Hristov, D. (2017) Developing Imaginators not Managers--How to Flip the Business School Model. The International Journal of Management Education, 15 (3), 481-489.

[4] Borges, J.C., Ferreira, T.C., Oliveira, M.S.B., Macini, N. and Caldana, A.C.F. (2017) Hidden Curriculum in Student Organizations: Learning, Practice, Socialization and Responsible Management in a Business School. The International Journal of Management Education, 15(2), 153-161.

[5] Sledgianowski, D., Gomaa, M., Tan, C. (2017) Toward Integration of Big Data, Technology and Information Systems Competencies into the Accounting Curriculum. Journal of Accounting Education, 38, 81-93. 